BIOMEDICAL AND BIOSOCIAL ANTHROPOLOGY
$\begin{gathered}\text { Official Journal of the International Academy } \\ \text { of Integrative Anthropology } \\ \text { journal homepage: http://bba-journal.com }\end{gathered}$

\title{
Girth body sizes in men with benign nevi
}

Nabil Basim Yousif Haddad, Dmytrenko S. V., Chernachuk S. V., Shapoval O. M., Mykhalchuk M. A. National Pirogov Memorial Medical University, Vinnytsya, Ukraine

\begin{tabular}{|c|c|}
\hline $\begin{array}{l}\text { ARTICLE INFO } \\
\text { Received: } 26 \text { March } 2021 \\
\text { Accepted: } 27 \text { April } 2021 \\
\text { UDC: } 616.5-003.829-037-084-07 \\
\text { CORRESPONDING AUTHOR } \\
\text { e-mail: nabil.basim@gmail.com } \\
\text { Nabil Basim Yousif Haddad }\end{array}$ & 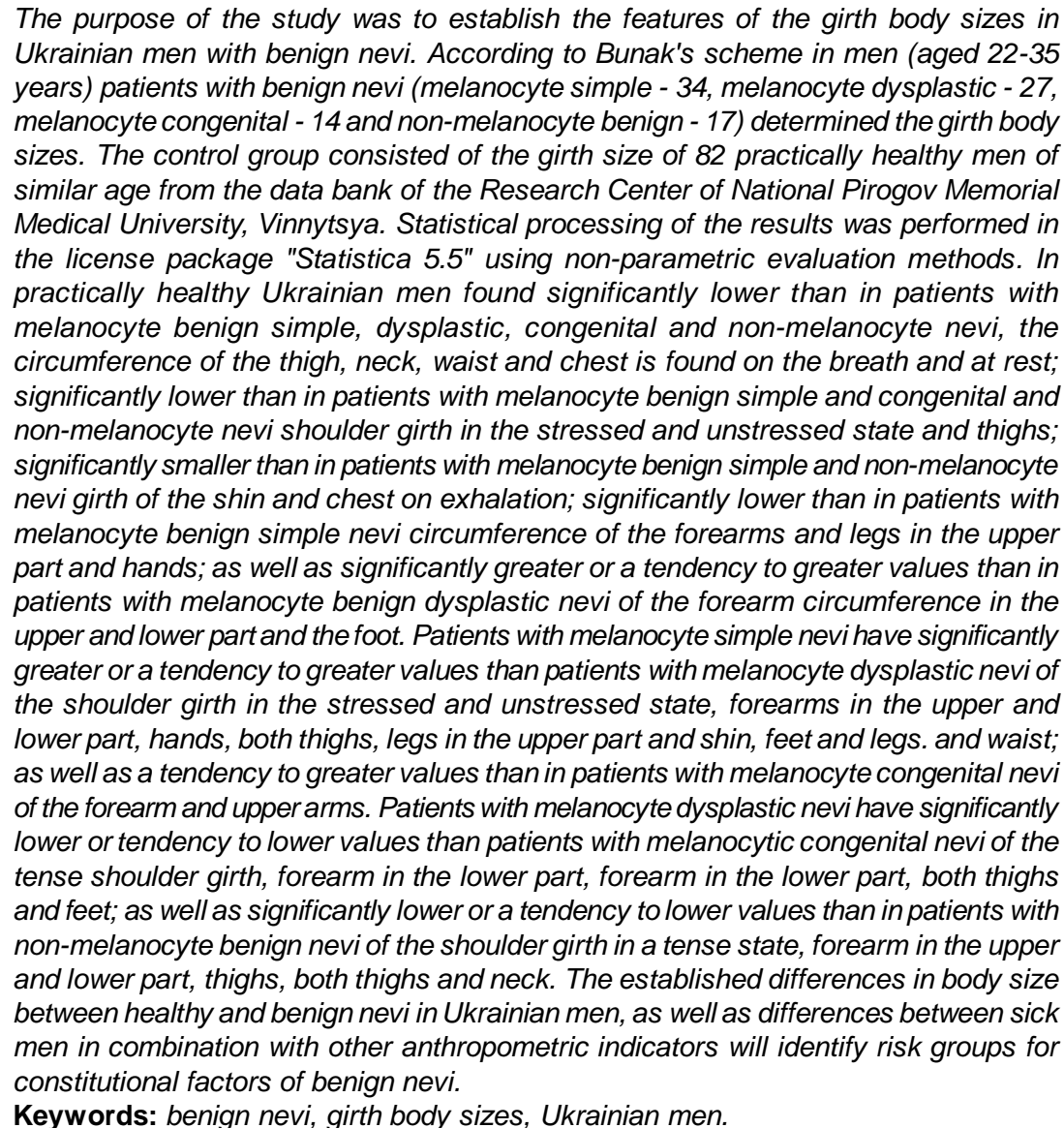 \\
\hline
\end{tabular}

\section{Introduction}

Benign nevi are neoplasms of the skin that have a variety of localization, shape and size, occur both at birth and at any time in life. These include benign simple, dysplastic, melanocyte and non-melanocyte nevi. Due to their benign nature, they usually do not require surgery, but regular supervision is necessary due to the possibility of malignancy $[8,18]$. Analysis of the data shows that the occurrence of primary melanoma is closely associated with an increased number of nevi (HR 2.91; $95 \% \mathrm{Cl} 1.94-4.35)$ [19].
Studies of acral melanocyte nevi have shown that their number gradually increases with the age of patients up to 60 years, after which there is a similar gradual decrease in their number [6].

Different genetic triggers are responsible for the development of certain types of nevi. Thus, acquired melanocyte nevi are characterized by BRAF mutations, congenital melanocyte nevi are characterized by NRAS mutations, blue nevus is characterized by GNAQ mutations, 
and Spitz nevus is characterized by HRAS [14].

Among all skin neoplasms, nevi are the most common [16]. Among newborns, the incidence of nevi ranges from 3 to $16 \%$, depending on race or ethnicity. Congenital nevi occur in 1-2.4\% of people, with a predominance of people in Africa and Japan, and less among Europeans and Latinos [4].

Heterogeneous nevi in men and women have also been reported. A study by Italian scientists showed a higher prevalence of nevi among boys $(p<0.05)$ and the most typical localizations of nevi - torso and neck $(p<0.001)$ [11].

A study of Becker's nevus revealed that in $59.8 \%$ the onset of the disease occurred at the age of $12-15$ years, and the most typical localization of this nevus was the upper part of the chest and shoulders (68.3\%). In addition, in $75.4 \%$ of cases this disease is accompanied by hypertrichosis [22].

Such a wide prevalence allows the use of nevi for various purposes, such as to identify individuals [1]. However, currently the priority for scientists is to find methods for predicting the occurrence of nevi, using various scientific approaches, in particular, constitutional.

The purpose of the study was to establish the features of the girth body sizes in Ukrainian men with benign nevi.

\section{Materials and methods}

Men aged 22 to 35 years, patients with benign nevi (including: with melanocyte benign simple nevi - 34; with melanocyte benign dysplastic nevi - 27; with melanocyte benign congenital nevi - 14; with non-melanocyte benign nevi - 17) had laboratory and histopathological examinations on the basis of the Military Medical Clinical Center of the Central Region and the Department of Dermatology and Venereal Diseases with a course of postgraduate education National Pirogov Memorial Medical University, Vinnytsya. All patients signed an informed consent to participate in the study.

The diagnosis of nevi was established according to a two-stage algorithm for the classification of pigmented tumors, which was adopted at the First World Congress of Dermatoscopy (Rome, 2001) [12].

All patients were determined girth body sizes according to the scheme of Bunak V. V. [2].

As a control from the database of the research center of the National Pirogov Memorial Medical University, Vinnytsya were selected comprehensive body size of 82 practically healthy men of the same age group.

Statistical processing of the results was performed in the license package "Statistica 5.5" using non-parametric evaluation methods. The reliability of the difference between the values between the independent quantitative values was determined using the U-Mann-Whitney test.

\section{Results}

It was found that the girth of the shoulder in a tense state in healthy men is significantly $(p<0.05-0.001)$ lower

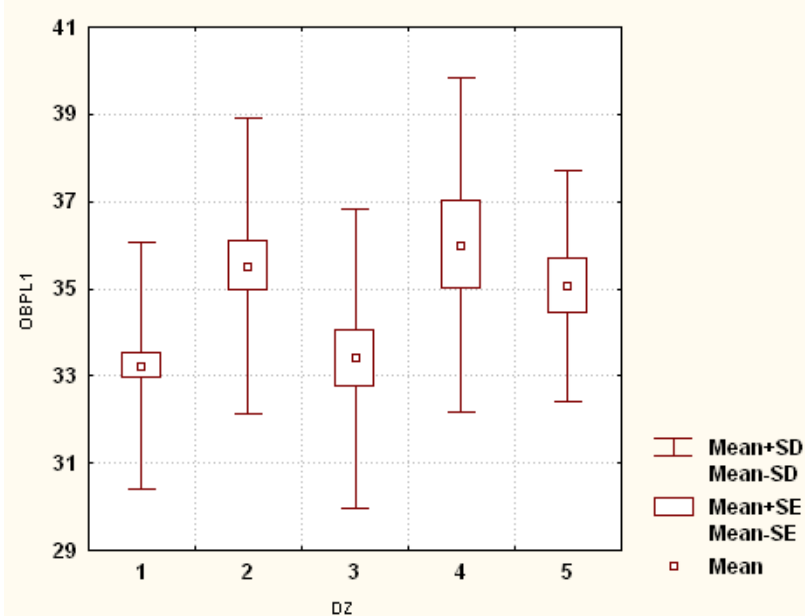

Fig. 1. Girth of tense shoulder (OBPL1) in healthy and sick men with benign nevi $(\mathrm{cm})$. In this and the following figures: DZ - the corresponding groups of men; 1 - healthy men; 2 - men with melanocyte benign simple nevi; 3 - men with melanocyte benign dysplastic nevi; 4 - men with melanocyte benign congenital nevi; 5 - men with non-melanocyte benign nevi; Mean - average value; Mean $\pm S E$ - average value \pm mean error; Mean $\pm S D$ - mean \pm standard deviation.

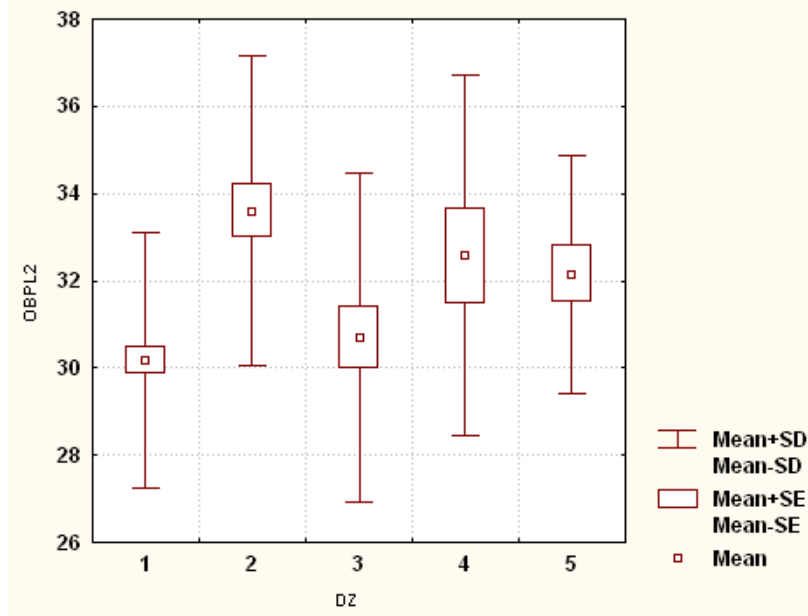

Fig. 2. Untense shoulder girth (OBPL2) in healthy and sick men with benign nevi $(\mathrm{cm})$.

than in men with melanocyte benign simple and congenital nevi and non-melanocyte benign nevi; and in men with melanocyte benign dysplastic nevi - significantly smaller $(p<0.05)$ than in patients with melanocyte benign simple and congenital nevi and tends to lower values $(p=0.075)$ than in patients with non-melanocyte benign nevi (Fig. 1).

The girth of the untense shoulder in healthy men is also significantly $(p<0.05-0.001)$ lower than in patients with melanocyte benign simple and congenital nevi and nonmelanocyte benign nevi; and in men with melanocyte benign dysplastic nevi - significantly lower $(p<0.05)$ than in patients with melanocyte benign simple nevi (Fig. 2).

Upper forearm girth in healthy men was significantly $(p<0.01)$ lower than in patients with melanocyte benign 


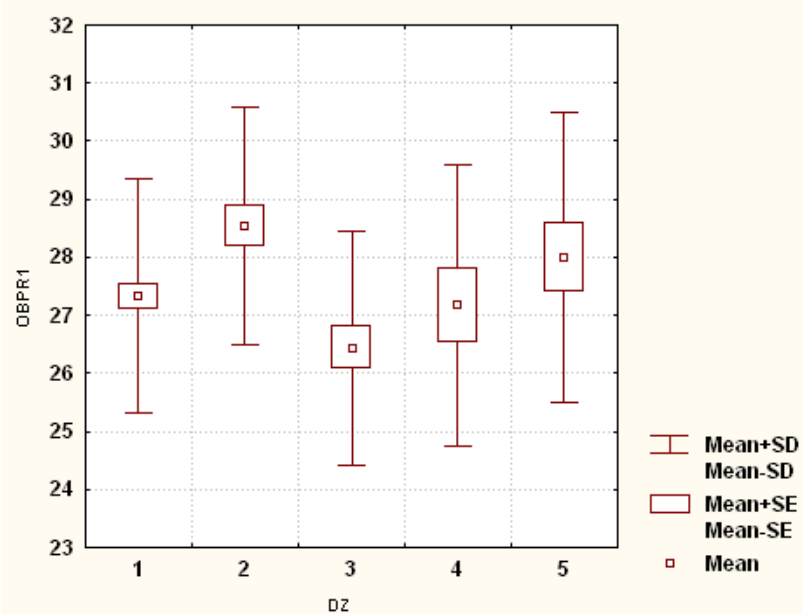

Fig. 3. Upper forearm girth (OBPR1) in healthy and sick men with benign nevi $(\mathrm{cm})$.

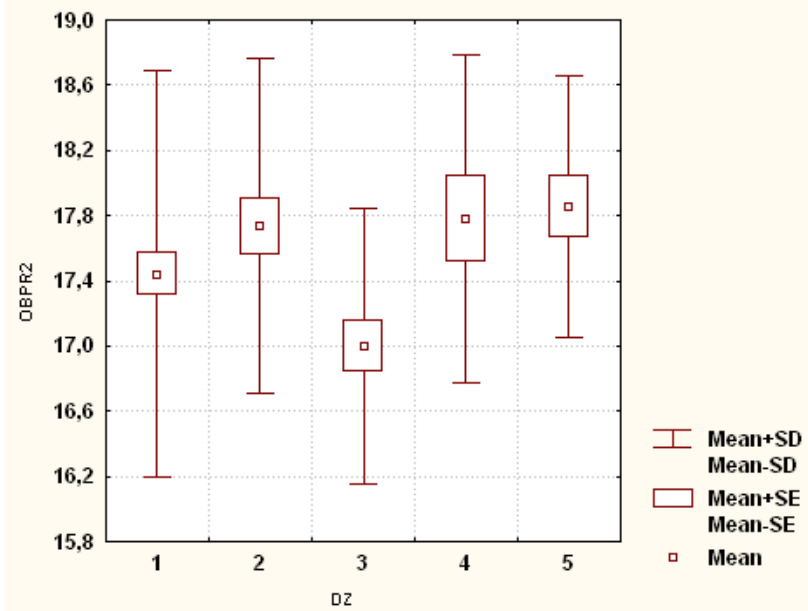

Fig. 4. Lower forearm girth (OBPR2) in healthy and sick men with benign nevi $(\mathrm{cm})$.

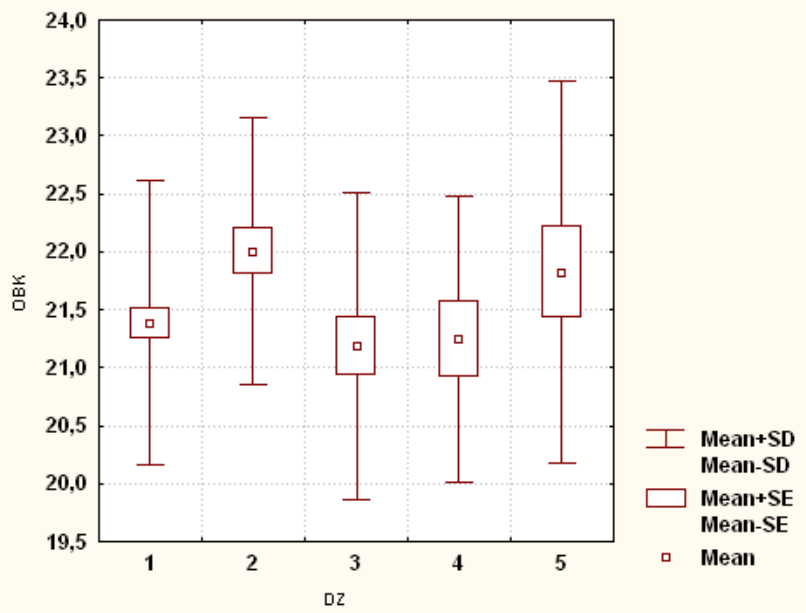

Fig. 5. Brush girth (OBK) in healthy and sick men with benign nevi (cm).

simple nevi and tended to be higher $(p=0.065)$ than in patients with melanocyte benign dysplastic nevi; and in

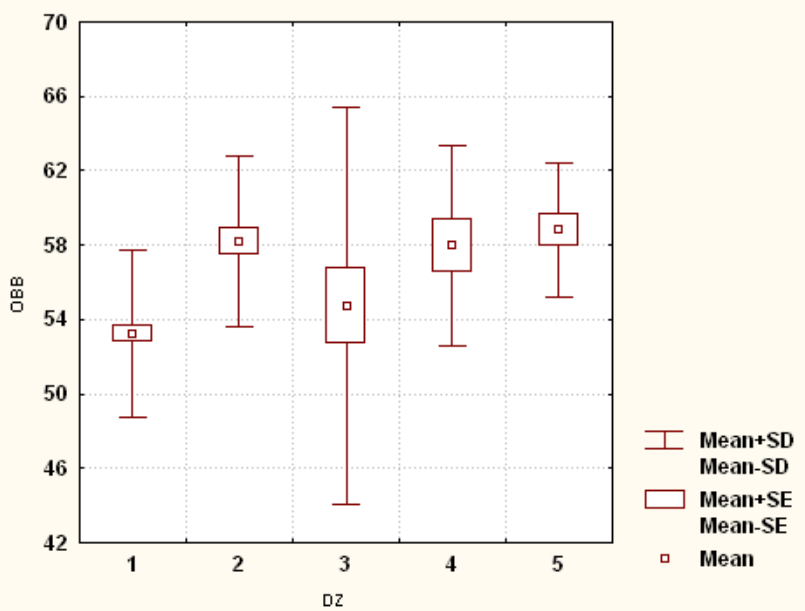

Fig. 6. Thigh girth (OBB) in healthy and sick men with benign nevi (cm).

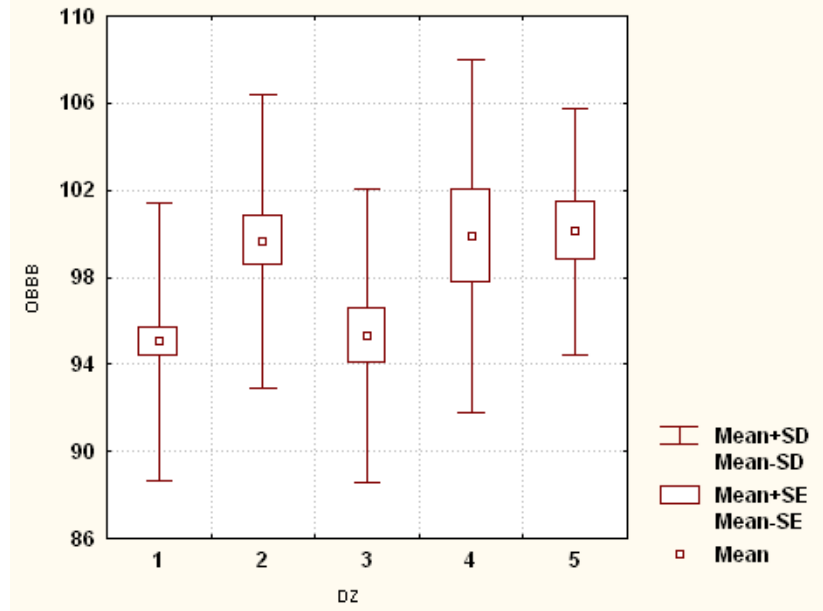

Fig. 7. Thighs girth (OBBB) in healthy and sick men with benign nevi $(\mathrm{cm})$.

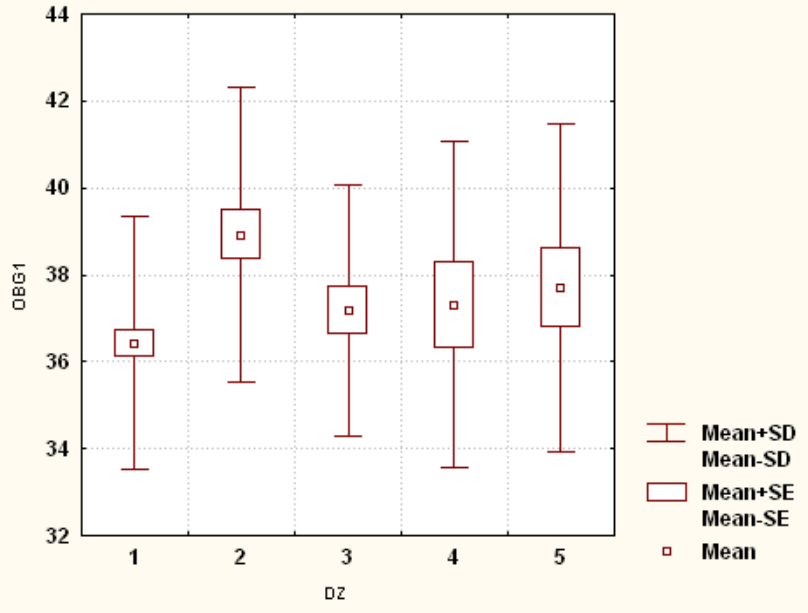

Fig. 8. Shin girth at the top (OBG1) in healthy and sick men with benign nevi $(\mathrm{cm})$.

men with melanocyte benign simple nevi - significantly higher $(p<0.001)$ than in patients with melanocyte benign 
dysplastic nevi and tends to higher values $(p=0.051)$ than in patients with melanocyte benign congenital nevi; as well as in men with melanocyte benign dysplastic nevi - tends to lower values $(p=0.075)$ than in patients with nonmelanocyte benign nevi (Fig. 3).

Forearm girth in the lower part in healthy men has only a slight tendency to higher values $(p=0.085)$ than in patients with melanocyte benign dysplastic nevi; and in men with melanocyte benign dysplastic nevi - significantly lower $(p<0.05-0.01)$ than in patients with melanocyte benign simple and congenital and non-melanocyte benign nevi (Fig. 4).

The girth of the hand in healthy men is significantly $(p<0.05)$ lower than in patients with melanocyte benign simple nevi; and in men with melanocyte benign simple nevi - significantly greater $(p<0.05)$ than in patients with melanocyte benign dysplastic nevi and tends to higher values $(p=0.065)$ than in patients with melanocyte benign congenital nevi (Fig. 5).

Hip girth in healthy men was significantly $(p<0.01-0.001)$ lower than in men with benign nevi; and men with melanocyte benign dysplastic nevi had tendency to lower values $(p=0.073)$ than in patients with non-melanocyte benign nevi (Fig. 6).

The girth of both thighs in healthy men was significantly $(p<0.05-0.01)$ lower than in men with melanocyte benign simple and congenital nevi and non-melanocyte benign nevi; and in men with melanocyte benign dysplastic nevi significantly lower $(p<0.05)$ than in patients with melanocyte benign simple and non-melanocyte benign nevi and has a slight tendency to lower values $(p=0.096)$ than in patients with melanocyte benign congenital nevi (Fig. 7).

Shin girth in the upper part in healthy men is significantly $(p<0.001)$ lower than in patients with melanocyte benign simple nevi; and in men with melanocyte benign dysplastic nevi - significantly lower $(p<0.05)$ than in patients with melanocyte benign simple nevi (Fig. 8).

The shin girth in healthy men was also significantly $(p<0.001)$ lower than in patients with melanocyte benign simple nevi; and in men with melanocyte benign dysplastic nevi - significantly smaller $(p<0.05)$ than in patients with melanocyte benign simple nevi (Fig. 9).

The girth of the foot in healthy men is significantly $(p<0.05)$ greater than in patients with melanocyte benign dysplastic nevi; and in men with melanocyte benign dysplastic nevi - significantly smaller $(p<0.01)$ than in patients with melanocyte benign simple nevi and has a slight tendency to lower values $(p=0.094)$ than in patients with melanocyte benign congenital nevi (Fig. 10).

Neck girth in healthy men was significantly $(p<0.001)$ lower than in men with benign nevi; and in men with melanocyte benign dysplastic nevi - significantly lower $(p<0.05)$ than in patients with non-melanocyte benign nevi (Fig. 11).

Waist circumference in healthy men was also significantly $(p<0.05-0.001)$ lower than in men with benign

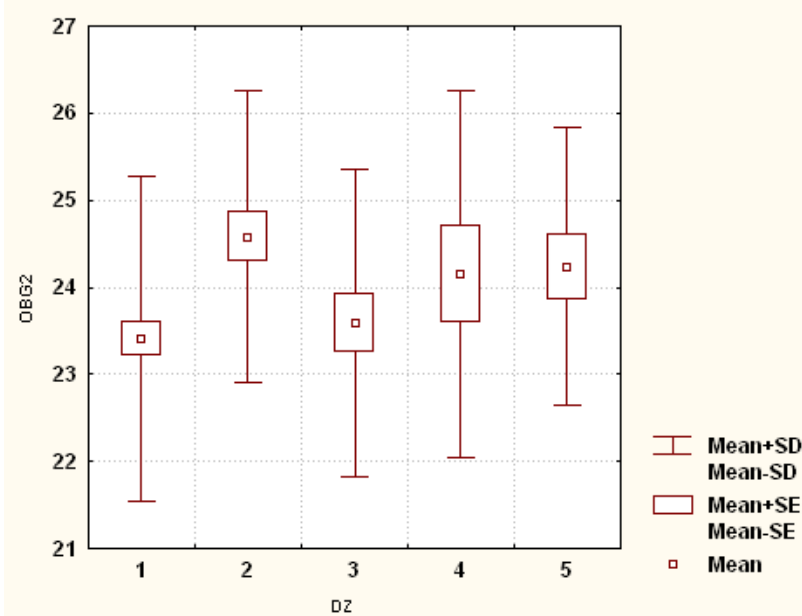

Fig. 9. Shin girth in the lower part (OBG2) in healthy and sick men with benign nevi $(\mathrm{cm})$.

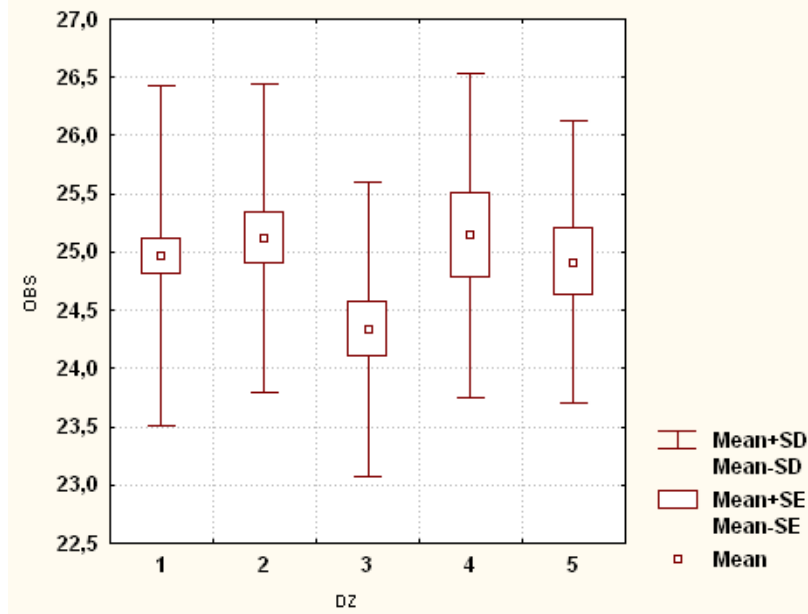

Fig. 10. Foot girth (OBS) in healthy and sick men with benign nevi (cm).

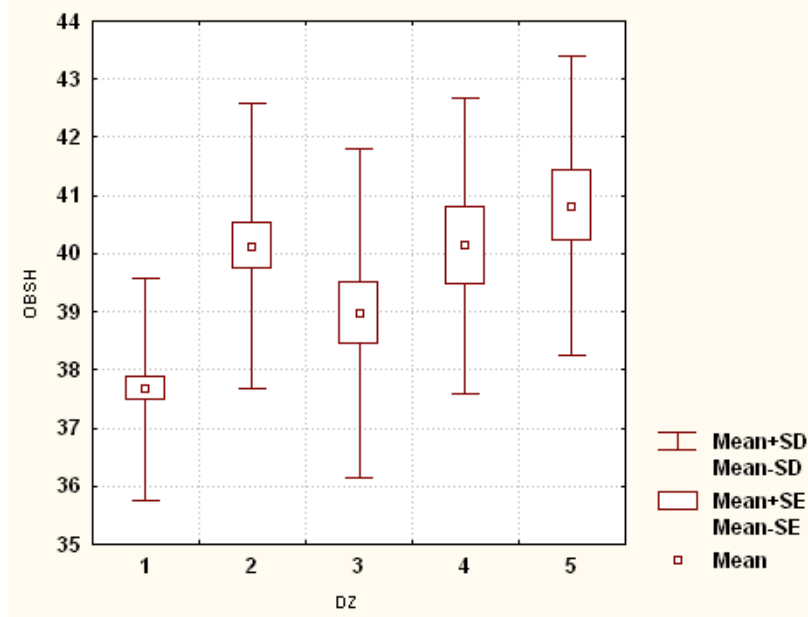

Fig. 11. Neck girth (OBSH) in healthy and sick men with benign nevi (cm).

nevi; and in men with melanocyte benign dysplastic nevi has a slight tendency to lower values $(p=0.081)$ than in 


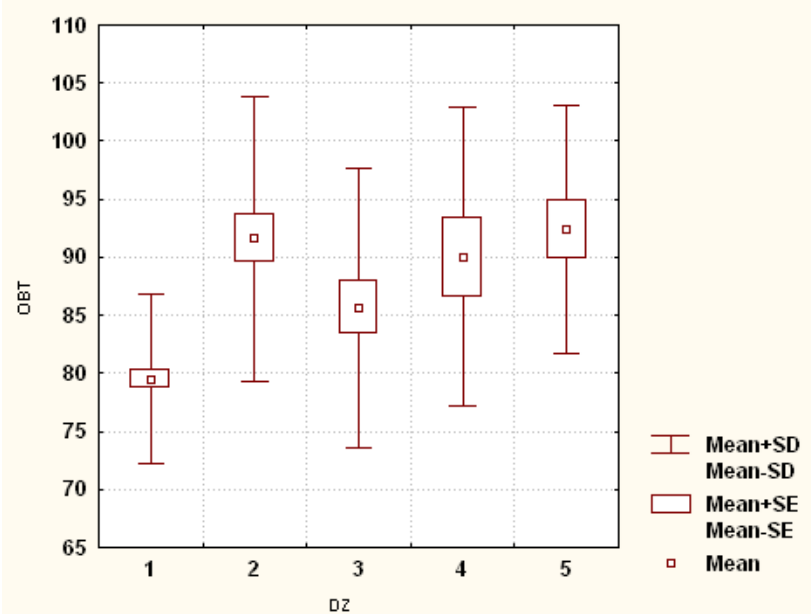

Fig. 12. Waist circumference (OBT) in healthy and sick men with benign nevi $(\mathrm{cm})$.

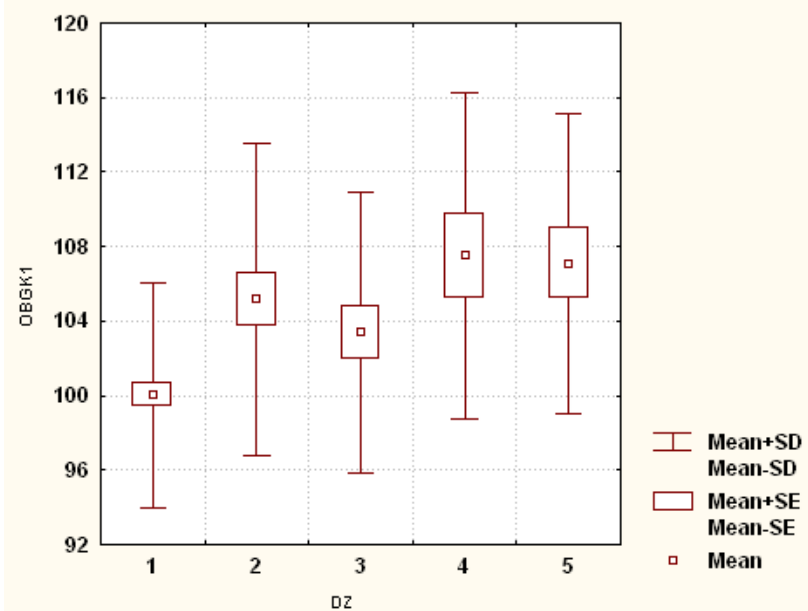

Fig. 13. Chest girth on inhalation (OBGK1) in healthy and sick men with benign nevi $(\mathrm{cm})$.

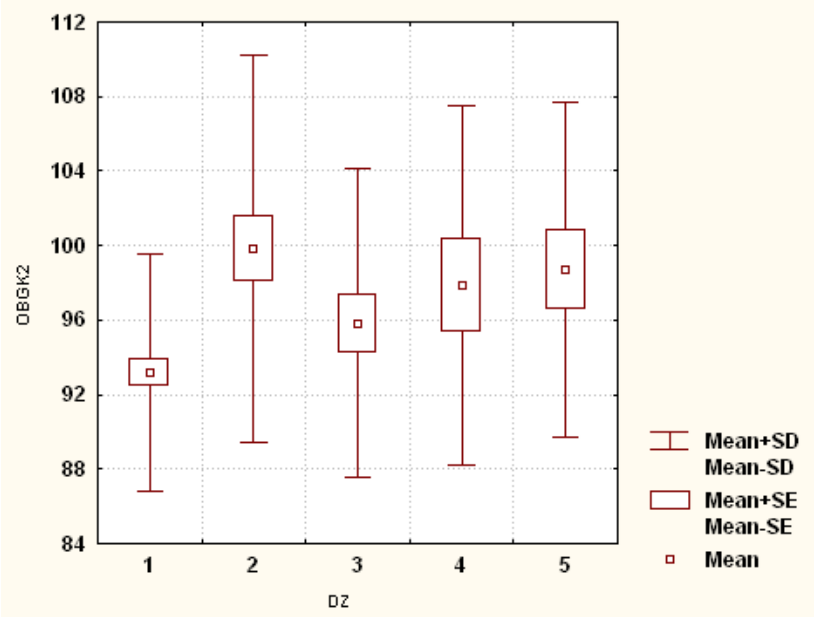

Fig. 14. Chest girth on exhalation (OBGK2) in healthy and sick men with benign nevi $(\mathrm{cm})$.

patients with melanocyte benign simple nevi (Fig. 12).

Chest girth on inspiration in healthy men is significantly

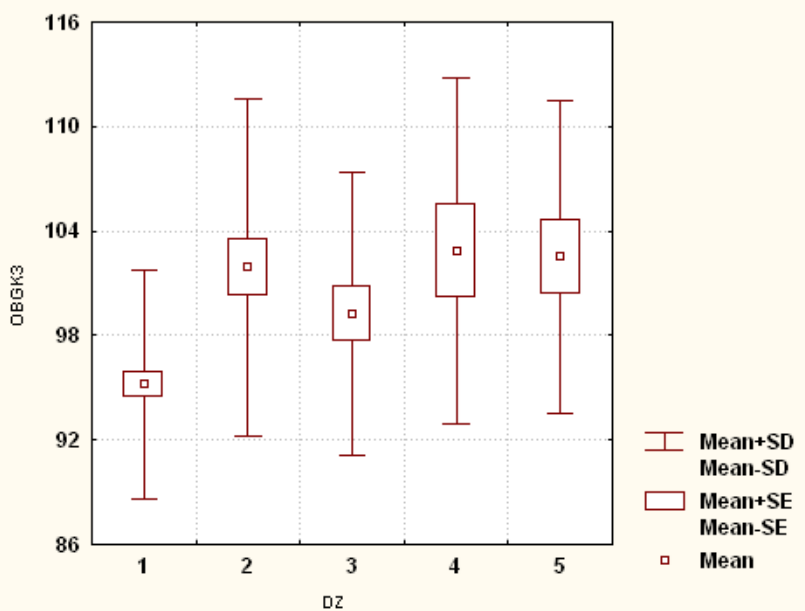

Fig. 15. Chest girth at rest (OBGK3) in healthy and sick men with benign nevi $(\mathrm{cm})$.

$(p<0.05-0.01)$ lower than in men with benign nevi (Fig. 13).

Chest girth on exhalation in healthy men is significantly $(p<0.05-0.001)$ lower than in men with melanocyte benign simple and non-melanocyte benign nevi (Fig. 14).

The chest girth at rest in healthy men is significantly $(p<0.05-0.001)$ lower than in men with benign nevi (Fig. 15).

\section{Discussion}

Thus, when analyzing the overall body size between healthy and benign nevi men found (Table 1):

- hip, neck, waist and chest girth on the inhale and at rest in healthy men is significantly lower than in patients with melanocyte benign simple nevi (8.5\%, $6.1 \%, 13.2 \%$, $4.9 \%$ and $6.6 \%$ respectively), melanocyte benign dysplastic nevi (respectively by $2.1 \%, 3.4 \%, 7.2 \%, 3.3 \%$ and $4.1 \%$ ), melanocyte benign congenital nevi (respectively by $8.2 \%, 6.2 \%, 11.7 \%, 7.0 \%$ and $7.5 \%$ ) and nonmelanocyte benign nevi (respectively $9.5 \%, 7.7 \%, 13.9 \%$, $6.6 \%$ and $7.1 \%)$;

- the girth of the shoulder in the tense and untense state and the hips in healthy men is significantly lower than in patients with melanocyte benign simple nevi $(6.4 \% 10.2$ $\%$ and $4.6 \%$, respectively), melanocyte benign congenital nevi (respectively $7.7 \% 7.4 \%$ and $4.8 \%$ ) and nonmelanocyte benign nevi $(5.2 \%, 6.2 \%$ and $5.1 \%$, respectively);

- thigh girth in lower part and chest girth on exhalation in healthy men was significantly lower than in patients with melanocyte benign simple nevi $(4.8 \%$ and $6.7 \%$, respectively) and non-melanocyte benign nevi (3.4\% and $5.6 \%$, respectively). .6\%);

- girth of the forearm and shin and hand in healthy men is significantly lower than in patients with melanocyte benign simple nevi (4.2\%, $6.4 \%$ and $2.8 \%$, respectively);

- the forearms girth in the upper and lower parts and the feet in healthy men are significantly larger or tend to be 
Table 1. Differences in girth body size between healthy and benign nevi patients, as well as between patient's men.

\begin{tabular}{|c|c|c|c|c|c|}
\hline \multirow{2}{*}{ Indicators } & \multirow{2}{*}{ Healthy } & \multicolumn{4}{|c|}{ Patients } \\
\hline & & MBSN & MBDN & MBCN & NMBN \\
\hline Shoulder girth in a tense state & & $\Delta \Delta$ & $\nabla \nabla \downarrow$ & $\Delta$ & $\uparrow$ \\
\hline Shoulder girth in a relaxed stat & & & & & \\
\hline Forearm girth at the top & & & $\downarrow$ & $\downarrow$ & $\uparrow$ \\
\hline Forearm girth at the bottom & & & $\nabla \nabla$ & $\Delta$ & $\Delta$ \\
\hline Brush girth & & & & & \\
\hline Thigh girth & & & $\downarrow$ & & $\uparrow$ \\
\hline Thighs girth & & $\Delta$ & $\nabla \nabla \downarrow$ & $\uparrow$ & $\Delta$ \\
\hline Shin girth at the top & & $\Delta \Delta$ & $\nabla$ & & \\
\hline Shin girth at the bottom & & $\Delta$ & $\nabla$ & & \\
\hline Foot girth & & & $\nabla \nabla \downarrow$ & $\uparrow$ & \\
\hline Neck girth & & & $\Delta \nabla$ & & $\Delta$ \\
\hline Waist girth & & & & & \\
\hline Chest girth on inhalation & & & & & \\
\hline Chest girth on exhalation & & & & & \\
\hline Chest girth at rest & & & & & \\
\hline
\end{tabular}

Notes: MBSN - melanocyte benign simple nevi; MBDN - melanocyte benign dysplastic nevi; MBCN - melanocyte benign congenital nevi; NMBN - non-melanocyte benign nevi; $\nabla$ or $\Delta$ - significant differences between healthy and sick men; $\uparrow$ or $\downarrow$ - trends in differences between healthy and sick men; $\Delta$ or $\nabla$ - significant differences in rates between MBSN men and other groups of sick men; $\uparrow$ or $\downarrow$ trends in differences between MBSN men and other groups of sick men; $\nabla$ or $\Delta$ - significant differences between MBDN men and MBCN or NMBN men; $\uparrow$ or $\downarrow$ - trends in differences between MBDN men and men with MBCN or NMBN.

higher than in patients with melanocyte benign dysplastic nevi (3.3\%, $2.5 \%$ and $2.5 \%$, respectively).

In the analysis of the comprehensive body sizes between different groups of patients with benign nevi of men found (see Table 1):

- significantly higher or a tendency to higher values in patients with melanocyte simple than in patients with melanocytic dysplastic nevi of the girth were found shoulder in tension by $5.9 \%$, shoulder in stress by $8.6 \%$, forearm in the upper part by $7.4 \%$, forearms in the lower part by $4.2 \%$, hands by $3.7 \%$, both thighs by $4.4 \%$, shins in the upper part by $4.4 \%$, shins in the lower part by $4.0 \%$, feet by $3.1 \%$ and waist by $6.5 \%$;

- tendency to higher values in patients with melanocytic simple nevi than in patients with melanocyte congenital nevi in girth - forearms in the upper part by $4.8 \%$ and hands by $3.5 \%$;

- significantly lower or tendency to lower values in patients with melanocytic dysplastic nevi than in patients with melanocytic congenital nevi in girth - the shoulder in a tense state by $7.2 \%$, the forearm in the lower part by $4.4 \%$, both thighs by $4.6 \%$ and foot to $3.2 \%$;

- significantly lower or a tendency to lower values in patients with melanocyte dysplastic nevi than in patients with non-melanocyte benign nevi in girth - the shoulder in a tense state by $4.7 \%$, the forearm at the top by $5.6 \%$, the forearm at the bottom by $4.8 \%$, hips by $7.0 \%$, both thighs by $4.8 \%$ and neck by $4.5 \%$.
Few studies are available in scientometric databases and search for the relationship between anthropometric indicators and the risk of skin cancer confirm our data [21]. Thus, a review of the literature by Cassano N. [3] and coauthors showed that the most encouraging and reliable data relate to the relationship between body mass index and Breslow's prediction of melanoma thickness.

A comparison of anthropometric and other data of patients under 20 years of age with melanoma of the skin and Spitz's nevus revealed that the latter have lower body mass index $(p=0.001)$, lower total number of nevi on the body $(p=0.002)$ and fewer freckles number $(p=0.020)$ [5].

Individuals with overweight and obesity have not only larger melanocyte nevi $(p<0.05)$ but also higher number. In addition, the relationship with freckles $(p<0.005)$ and light skin color $(p<0.001)$ was found as in the previous study [9].

As a result of 16 years of follow-up of more than 500 people, of whom 28 were diagnosed with primary melanoma, an association was found between the growth and risk of melanoma in both men and women $(R R=1.66$; $95 \% \mathrm{Cl}=1.11-2.48$, for $\geq 175 \mathrm{~cm}$ vs. $\leq 171 \mathrm{~cm}$, Ptrend $=0.017$ and Ptrend=0.043, respectively) [10].

Analysis of the results of 21 studies confirmed the relationship between body mass index and body surface area and the risk of melanoma, but only for men [15].

Elevated body mass index is associated with an increased risk of choroidal nevus in both men and the general population (OR: 1.43, Cl: 1.03-1.99, $\mathrm{p}=0.03$ and 
OR: 1.35, $95 \% \mathrm{Cl}: 1.06-1.71, \mathrm{p}=0.01$, respectively) but not in women [17].

A long-term study (1972-2003) on a large sample of Norwegians (292,851 people) revealed 3,000 cases of melanoma during the observation period. Taking into account anthropometric data and statistical data processing allowed to establish a relationship between the occurrence of melanoma and an increase in body mass index, body surface area, height, weight $(<0.001$ in all cases) [20].

At the same time, the relationship of the reverse force between overweight and the risk of non-melanoma types of human skin cancer has been established. Thus, obese individuals are less likely to develop squamous cell and basal cell carcinoma of the skin [13].

The mechanism of the relationship between weight gain and an increased risk of certain skin cancers (including melanoma) is primarily due to the association between

\section{References}

[1] Black, S., MacDonald-McMillan, B., Mallett, X., Rynn, C., \& Jackson, G. (2014). The incidence and position of melanocytic nevi for the purposes of forensic image comparison. International Journal of Legal Medicine, 128(3), 535-543. doi: 10.1007/s00414-013-0821-z

[2] Bunak, V. V. (1941). Антропометрия [Anthropometry]. M.: Наркомпрос РСФСР - M.: People's Commissariat of the RSFSR.

[3] Cassano, N., Caccavale, S., Vena, G. A., \& Argenziano, G. (2021). Body mass index and melanoma prognosis. Dermatology Practical \& Conceptual, 11(4), e2021106. doi: $10.5826 / \mathrm{dpc} .1104 \mathrm{a} 106$

[4] del Carmen Boente, M. (2015). Congenital melanocytic nevi. In Pediatric skin of color (pp. 249-260). Springer, New York, NY.

[5] Fortes, C., Mastroeni, S., Capuano, M., Ricozzi, I., Bono, R., Ricci, F., ... \& Nudo, M. (2021). Differences in individual and environmental factors between cutaneous melanoma and atypical Spitz tumour in children and adolescents. European journal of pediatrics, 1-7. doi: 10.1007/s00431-021-04302-w

[6] Jin, H., Kim, G. W., Kim, W. J., Song, M., Kim, R. S., Ko, H. C., ... \& Mun, J. H. (2015). A study of the prevalence, distribution and dermoscopic patterns of acral melanocytic nevi in a Korean Population. Korean Journal of Dermatology, 53(8), 612-616.

[7] Karimi, K., Lindgren, T. H., Koch, C. A., \& Brodell, R. T. (2016). Obesity as a risk factor for malignant melanoma and nonmelanoma skin cancer. Reviews in Endocrine and Metabolic Disorders, 17(3), 389-403. doi: 10.1007/s11154-016-9393-9

[8] Katoulis, A. C., Sgouros, D., \& Stavrianeas, N. G. (2015). Nevi (Benign Melanocytic). In European Handbook of Dermatological Treatments (pp. 643-663). Springer, Berlin, Heidelberg.

[9] Kontautiene, S., Stang, A., Gollnick, H., \& Valiukeviciene, S. (2015). The role of phenotype, body mass index, parental and sun exposure factors in the prevalence of melanocytic nevi among schoolchildren in Lithuania. Journal of the European Academy of Dermatology and Venereology, 29(8), 1506-1516. doi: $10.1111 /$ jdv. 12905

[10] Lahmann, P. H., Hughes, M. C. B., Williams, G. M., \& Green, A. C. (2016). A prospective study of measured body size and height and risk of keratinocyte cancers and melanoma. Cancer epidemiology, 40, 119-125. doi: 10.1016/j.canep.2015.12.006

[11] Patruno, C., Scalvenzi, M., Megna, M., Russo, I., Gaudiello, F. \& Balato, N. (2014). Melanocytic nevi in children of southern adipose tissue and pigmentation, as demonstrated in POMC mutations [7].

That is, the application of a constitutional approach to predict the occurrence of benign nevi is the most appropriate and pathogenetically justified.

\section{Conclusion}

1. In most cases, practically healthy Ukrainian men have significantly lower values of girth body sizes (except for forearms and feet) than in patients with benign nevi (most pronounced with patients with melanocyte benign simple and non-melanocyte benign nevi).

2. Among men with various forms of benign nevi, in most cases, significantly smaller or a tendency to lower values of most of the girth body sizes (excluding chest girth) in patients with melanocyte benign dysplastic nevi (most pronounced with patients with melanocyte benign and nonmelanocyte benign nevi).

Italy: dermoscopic, constitutional, and environmental factors. Pediatric dermatology, 31(1), 38-42. doi: 10.1111/pde.12119

[12] Potekayev, N. N., Shuginina, Y. K., Kuzmina, T. S., \& Arutyunyan, L. S. (2011). Дерматоскопия в клинической практике. Рyководство для врачей [Dermatoscopy in clinical practice. A guide for doctors]. M: МДВ, 144 - M: MDV, 144.

[13] Pothiawala, S., Qureshi, A. A., Li, Y., \& Han, J. (2012). Obesity and the incidence of skin cancer in US Caucasians. Cancer causes \& control, 23(5), 717-726. doi: 10.1007/s10552-0129941-X

[14] Roh, M. R., Eliades, P., Gupta, S., \& Tsao, H. (2015). Genetics of melanocytic nevi. Pigment cell \& melanoma research, 28(6), 661-672. doi: 10.1111/pcmr.12412

[15] Sergentanis, T. N., Antoniadis, A. G., Gogas, H. J., Antonopoulos, C. N., Adami, H. O., Ekbom, A., \& Petridou, E. T. (2013). Obesity and risk of malignant melanoma: a meta-analysis of cohort and case-control studies. European journal of cancer, 49(3), 642-657. doi: $10.1016 /$ j.ejca.2012.08.028

[16] Shields, C. L., Sioufi, K., Alset, A. E., Boal, N. S., Casey, M. G., Knapp, A. N., ... \& Shields, J. A. (2017). Clinical features differentiating benign from malignant conjunctival tumors in children. JAMA ophthalmology, 135(3), 215-224. doi: 10.1001/ jamaophthalmol.2016.5544

[17] Sieburth, R. M., Qiu, M., \& Shields, C. L. (2015). Sex differences in the relationship between obesity and choroidal nevus in US adults. Investigative ophthalmology \& visual science, 56(12), 7489-7495. doi: 10.1167/iovs. 15-17803

[18] Simons, E. A., Huang, J. T., \& Schmidt, B. (2017). Congenital melanocytic nevi in young children: Histopathologic features and clinical outcomes. Journal of the American Academy of Dermatology, 76(5), 941-947. doi: 10.1016/j.jaad.2016.12.026

[19] Siskind, V., Hughes, M. C. B., Palmer, J. M., Symmons, J. M., Aitken, J. F., Martin, N. G., ... \& Whiteman, D. C. (2011). Nevi, family history, and fair skin increase the risk of second primary melanoma. Journal of investigative dermatology, 131(2), 461467. doi: $10.1038 /$ jid.2010.298

[20] Stenehjem, J. S., Veierød, M. B., Nilsen, L. T., Ghiasvand, R., Johnsen, B., Grimsrud, T. K., ... \& Robsahm, T. E. (2018). Anthropometric factors and cutaneous melanoma: prospective data from the population-based Janus Cohort. International journal of cancer, 142(4), 681-690. doi: 10.1002/ijc.31086 
[21] Tang, J. Y., Henderson, M. T., Hernandez-Boussard, T., Kubo, J., Desai, M., Sims, S. T., ... \& Stefanick, M. L. (2013). Lower skin cancer risk in women with higher body mass index: the women's health initiative observational study. Cancer Epidemiology and Prevention Biomarkers, 22(12), 2412-2415. doi: 10.1158/1055-9965.EPI-13-0647

[22] Tawara, M. J. (2013). Prevalence and clinical characteristics of Becker's Nevi in young Jordanian males, J. Country: Jordan, 20(4), 57-62. 